\title{
Synthesis and Characterization of New Comb-Like Aromatic Polyamides, Polyimides, and Polyureas Containing 1,3,5-Triazine Rings in their Side Chains
}

\author{
Jui-Kun LIN, Yasuo Y UKI, ${ }^{*}$ Hideo KUNISADA, \\ Chikara MiYagawa, and Shuji Kondo \\ Department of Materials Science and Engineering, \\ Nagoya Institute of Technology, \\ Gokiso-cho, Showa-ku, Nagoya 466, Japan
}

(Received March 30, 1989)

\begin{abstract}
New comb-like aromatic polyamides, polyimides, and polyureas containing the 1,3,5-triazine ring with two long alkyl groups in the side chain (DA18-polymers) were synthesized by the reaction of $m$-phenylene diamine derivative, that is, 2,4-bis( $N$-octadecylanilino)-6-(3,5diaminophenyl)-1,3,5-triazine (DA18) with aromatic diacid chlorides, pyromellitic dianhydride, and diisocyanates. Making reference to DA18-polymers, the DA-polymers without long alkyl chains were also prepared by the reaction of 2,4-dianilino-6-(3,5-diaminophenyl)-1,3,5-triazine (DA) with the above comonomers, respectively. The DA18-polymers were soluble in tetrahydrofuran, chloroform and toluene, but insoluble in polar aprotic solvents. The DA-polymers were stable up to $430^{\circ} \mathrm{C}$ for polyamides, $480^{\circ} \mathrm{C}$ for polyimide, and $300^{\circ} \mathrm{C}$ for polyureas. DA18-polymers with long alkyl groups showed lower thermal stability than DA-polymers. The DA18-polymers showed side-chain crystallization based on long alkyl groups, and the degree of crystallinity was found to depend on the main chain structure.

KEY WORDS 1,3,5-Triazine / Comb-Like Polymer / Polyamide / Polyimide

/ Polyurea / Long Alkyl Group / Side-Chain Crystallization /
\end{abstract}

It has been reported that polymers having $n$ alkyl groups with at least four carbon atoms in the side chain can undergo side-chain crystallization. ${ }^{1,2}$ A lot of papers describe the relations between the properties and the structures of these so-called comb-like polymers prepared by the homo-and copolymerization of vinyl compounds. $^{3-5}$ There are very few studies on aromatic polymers having long side chains by polycondensation. Takayanagi et al.$^{6,7}$ reported the alkylation of poly ( $p$-phenylene terephthalamide) (PPTA), the $N$-octadecylated PPTA showed the side-chain crystallization and the liquid crystalline behavior of lyotropic type, but led to a decrease in thermal stability by the introduction of long alkyl groups into the amide groups of aromatic PPTA.

Recently, we reported the preparation and properties of novel aromatic polymers containing 1,3,5-triazine with long alkyl groups in the polymer main chain. ${ }^{8}$ The introduction of long alkyl side chains in the polymer chain led to an obvious change in their solubility, and almost no effect on thermal stability compared with those of corresponding polymers without long alkyl side chains. In addition, the long alkyl side chains of these polymers have been observed to form crystals by measurement of differential scanning calorimetry. Consequent$1 y$, it is expected that the incorporation of 1,3,5-triazine with long alkyl groups in polymer side chain should also lead to modifica-

\footnotetext{
* To whom all correspondence should be addressed.
} 
tion of the aromatic polymer.

This paper reports the synthesis and properties of aromatic polyamides, polyimides, and polyureas containing 1,3,5-triazine with two long alkyl groups in the polymer side chain.

\section{EXPERIMENTAL}

\section{Materials}

1,5-Diphenylbiguanide was prepared by the reaction of phenyldicyanodiamide with aniline hydrochloride according to the literature. ${ }^{9}$ The solvents used for reactions such as dimethyl sulfoxide (DMSO), $N$-methyl-2-pyrrolidone (NMP), $\quad N, N^{\prime}$-dimethylacetamide (DMAc), and tetrahydrofuran (THF) were purified by distillation. Terephthaloyl chloride (TC), isophthaloyl chloride (IC), pyromellitic dianhydride (PA), 4,4'-diphenylmethane diisocyanate (MI), toluene 2,4-diisocyanate (TI), and 3,5dinitrobenzoyl chloride were used as received.

\section{2,4-Dianilino-6-(3,5-dinitrophenyl)-1,3,5-tri- azine $(D N)$}

$35.6 \mathrm{~g}(0.15 \mathrm{~mol})$ of 3,5-dinitrobenzoyl chloride was added dropwise to a stirred solution of $76.0 \mathrm{~g}(0.30 \mathrm{~mol})$ of 1,5-diphenylbiguanide in $450 \mathrm{ml}$ of acetone at $0-5^{\circ} \mathrm{C}$. The reaction was then continued at $0-5^{\circ} \mathrm{C}$ for $4 \mathrm{~h}$ and at room temperature for one night. The precipitate was separated and washed thoroughly with hot water to take off the biguanide hydrochloride. The crude product was recrystallized from 2-methoxyethanol to give $38.5 \mathrm{~g}$ $(59 \%)$ of pure DN with $\mathrm{mp} 257^{\circ} \mathrm{C}$. Anal. Calcd for $\mathrm{C}_{21} \mathrm{H}_{15} \mathrm{~N}_{7} \mathrm{O}_{4}$ : C, $58.74 \% ; \mathrm{H}, 3.52 \%$; $22.83 \%$. Found: C, $58.42 \%$; H, 3.45\%; H, $22.55 \%$. ${ }^{1} \mathrm{H}$ NMR (DMSO- $d_{6}$ ): $10.20 \mathrm{ppm}(\mathrm{s}$, $2 \mathrm{H},-\mathrm{NH}-$ of anilino); $7.25-9.51 \mathrm{ppm} \mathrm{(m}$, $13 \mathrm{H}$, aromatic protons).

\section{2,4-Dianilino-6-(3,5-diaminophenyl)-1,3,5-tri- azine $(D A)$}

$26.0 \mathrm{~g}(0.06 \mathrm{~mol})$ of $\mathrm{DN}$ was added to a stirred suspension of ferrous sulfate $(40 \mathrm{~g})$ and iron powder $(80 \mathrm{~g})$ in ethanol-water $(300 \mathrm{ml}$ :
$100 \mathrm{ml}$ ). This suspension was then separated after $5 \mathrm{~h}$ of stirring and refluxing at $85^{\circ} \mathrm{C}$, and the filtrate was poured into a large quantity of water at $0-5^{\circ} \mathrm{C}$. It was then filtered, dried, and recrystallized from methanol to give $18.8 \mathrm{~g}$ $(85 \%)$ of DA with mp $217^{\circ} \mathrm{C}$. Anal. Calcd for $\mathrm{C}_{21} \mathrm{H}_{19} \mathrm{~N}_{7}$ : C, $68.28 \%$; H, 5.18\%; N, $26.54 \%$. Found: C, $68.42 \%$; H, 5.03\% $\mathrm{N}, 26.47 \%{ }^{\circ}{ }^{1} \mathrm{H}$ NMR (DMSO- $\left.d_{6}\right): 9.20 \mathrm{ppm}(\mathrm{s}, 2 \mathrm{H},-\mathrm{NH}-$ of anilino); $4.88 \mathrm{ppm}\left(\mathrm{s}, 4 \mathrm{H},-\mathrm{NH}_{2}\right) ; 6.10-$ $8.10 \mathrm{ppm}(\mathrm{m}, 13 \mathrm{H}$, aromatic protons).

\section{2,4-Bis( N-octadecylanilino)-6-(3,5-diamino- phenyl)-1,3,5-triazine (DA18)}

$10.0 \mathrm{~g}(0.027 \mathrm{~mol})$ of DA was added to a stirred solution of $2.4 \mathrm{~g}(0.060 \mathrm{~mol})$ of sodium hydride $(60 \%$ oil suspension $)$ in $200 \mathrm{ml}$ of DMSO at $40^{\circ} \mathrm{C}$. After $1 \mathrm{~h}, 18.0 \mathrm{~g}(0.054 \mathrm{~mol})$ of $n$-octadecyl bromide was added to this solution at $40^{\circ} \mathrm{C}$. The mixture was stirred at $40^{\circ} \mathrm{C}$ for $6 \mathrm{~h}$ and at room temperature for one night. The precipitated product was separated, washed with water, and recrystallized from hexane to give $20.7 \mathrm{~g}(88 \%)$ of DA18 with mp $78^{\circ} \mathrm{C}$. Anal. Calcd for $\mathrm{C}_{57} \mathrm{H}_{91} \mathrm{~N}_{7}$ : C, $78.29 \%$; H, $10.49 \%$; N, $11.21 \%$. Found: C, $78.16 \% ; \mathrm{H}, 10.31 \% ; \mathrm{N}, 10.98 \%$. ${ }^{1} \mathrm{H}$ NMR $\left(\mathrm{CDCl}_{3}\right): 3.40 \mathrm{ppm}\left(\mathrm{s}, 4 \mathrm{H},-\mathrm{NH}_{2}\right) ; 3.90 \mathrm{ppm}$ $\left(\mathrm{t}, 4 \mathrm{H}, \mathrm{N}-\mathrm{CH}_{2}-\right) ; 1.10-1.40 \mathrm{ppm}(\mathrm{m}, 64 \mathrm{H}$, $\left.-\left(\mathrm{CH}_{2}\right)_{16}-\right) ; 0.88 \mathrm{ppm}\left(\mathrm{t}, 6 \mathrm{H},-\mathrm{CH}_{3}\right) ; 6.09-$ $7.33 \mathrm{ppm}$ (m, 13H, aromatic protons).

\section{Preparation of Polymers}

Polyamide DA-TC. $0.275 \mathrm{~g}(1.35 \mathrm{mmol})$ of TC was added to a stirred solution of $0.50 \mathrm{~g}$ $(1.35 \mathrm{mmol})$ of DA in $10 \mathrm{ml}$ of DMAc under a nitrogen atmosphere at room temperature. After $24 \mathrm{~h}$, the solution was poured into $300 \mathrm{ml}$ of methanol. The precipitated DA-TC was washed with methanol and dried. The yield was $0.628 \mathrm{~g}(93 \%)$. DA-TC was purified by reprecipitation from DMAc into methanol.

Polyamide DA18-TC. DA18 (1.06 g, 1.20 $\mathrm{mmol})$ was dissolved in $10 \mathrm{ml}$ of THF-NMP (1:1 volume) with stirring, and TC $(0.244 \mathrm{~g}$, $1.20 \mathrm{mmol}$ ) was added to this solution under 
a nitrogen atmosphere at room temperature. After $24 \mathrm{~h}$, the solution was poured into $300 \mathrm{ml}$ of methanol. DA18-TC was obtained after being washed with methanol and dried. The yield was $1.20 \mathrm{~g}(99 \%)$. Reprecipitation of DA18-TC was carried out from THFNMP into methanol.

Other polyamides DA-IC and DA18-IC were prepared in a similar manner.

Polyimide DA-PI. PA $(0.442 \mathrm{~g}, 2.03$ mmol) was added to a stirred solution of DA $(0.750 \mathrm{~g}, 2.03 \mathrm{mmol})$ in DMAc $(12 \mathrm{ml})$ at room temperature. After $24 \mathrm{~h}$, the solution was poured into $300 \mathrm{ml}$ of methanol. The resulting polyamic acid (DA-PA) was washed with methanol and dried. The yield was $1.03 \mathrm{~g}$ $(86 \%)$. Reprecipitation of DA-PA was carried out from DMAc into methanol. DA-PI was then prepared by heating the DA-PA at $200^{\circ} \mathrm{C}$ for $6 \mathrm{~h}$ in vacuo.

Polyimide DA18-PI. DA18 (1.06 g, 1.20 $\mathrm{mmol})$ and PA $(0.262 \mathrm{~g}, 1.20 \mathrm{mmol})$ were reacted in $10 \mathrm{ml}$ of THF-NMP (1:1 volume) at room temperature. After $24 \mathrm{~h}$, the solution was poured into $300 \mathrm{ml}$ of methanol to give the polyamic acid (DA18-PA). The yield was $1.29 \mathrm{~g}(98 \%)$. DA18-PA was reprecipitated from THF into methanol. DA18-PI was prepared by heating the DA18-PA at $200^{\circ} \mathrm{C}$ for $6 \mathrm{~h}$ in vacuo.

Polyurea DA-MI. MI $(0.338 \mathrm{~g}, 1.35 \mathrm{mmol})$ was added to a stirred solution of DA $(0.50 \mathrm{~g}$, $1.35 \mathrm{mmol})$ in DMAc $(10 \mathrm{ml})$ at room temperature. After $24 \mathrm{~h}$, the solution was poured into methanol $(300 \mathrm{ml})$ to give $0.83 \mathrm{~g}(99 \%)$ of DA-MI. DA-MI was reprecipitated from DMAc into methanol.

Polyurea DA18-MI. DA18 (1.06 g, 1.20 $\mathrm{mmol})$ and $\mathrm{MI}(0.30 \mathrm{~g}, 1.20 \mathrm{mmol})$ were reacted in $10 \mathrm{ml}$ of THF-NMP (1:1 volume) at room temperature. After $24 \mathrm{~h}$, the solution was poured into $300 \mathrm{ml}$ of methanol to give $1.33 \mathrm{~g}(98 \%)$ of DA18-MI. DA18-MI was reprecipitated from THF-NMP into methanol.

Other polyureas DA-TI and DA18-TI were prepared in a similar manner.

\section{Measurements}

A Hitachi 285 Infrared Spectrometer, a Hitachi R600 $(60 \mathrm{MHz})$ proton NMR spectrometer, and a Yanaco CHN corder MT-3 elemental analyzer were used to identify the structures of the monomers and polymers. A Rigaku TG-DTA $8112 \mathrm{BH}$ thermogravimeter connected to a differential thermal analysis system was used to study thermal stability. A Rigaku DSC-813BL differential scanning calorimeter (DSC) was used to study the sidechain crystallization of polymers. The reduced viscosities of polymers were determined in DMAc for DA-polymers and in THF-NMP (1:1 volume) for DA18-polymers at $30^{\circ} \mathrm{C}$ using an Ostwald viscometer. The solution concentration was $0.2 \mathrm{~g} \mathrm{dl}^{-1}$.

\section{RESULTS AND DISCUSSION}

\section{Synthesis of Diamines}

2,4-Dianilino-6-(3,5-diaminophenyl)-1,3,5triazine (DA) and 2,4-bis( $N$-octadecylanilino)6-(3,5-diaminophenyl)-1,3,5-triazine (DA18) were prepared according to Scheme 1.

The structure of DA and DA18 was confirmed by IR, ${ }^{1} \mathrm{H}$ NMR spectra and elemental analysis. IR spectra of DA showed absorption bands of $\mathrm{N}-\mathrm{H}$ stretching vibrations of anilino groups at $3450-3480 \mathrm{~cm}^{-1}$. These bands disappeared after alkylation, and new absorption bands of octadecyl groups of DA18 were observed at 2860 and $2920 \mathrm{~cm}^{-1}$. Further, both DA and DA1 8 showed absorption bands of the triazine ring at 1410 and $820 \mathrm{~cm}^{-1}, 8$ and $\mathrm{NH}_{2}$ groups at $3250-3600 \mathrm{~cm}^{-1}$. Data for ${ }^{1} \mathrm{H}$ NMR absorptions and elemental analyses are provided in Experimental. The structure of these diamine compounds was characterized from these data.

\section{Preparation of Polymers}

Scheme 2 shows the preparation of DApolymers and DA18-polymers by a solution 


$$
\begin{aligned}
& \text { (0) }{ }_{\mathrm{NHCNHCNH}}^{\mathrm{NH}}-\mathrm{O}+\mathrm{C}_{2}^{\mathrm{N}}-\widehat{\mathrm{OCl}}_{\mathrm{NO}_{2}}^{\rightarrow} \\
& \text { DN } \\
& \stackrel{\mathrm{DN}}{\mathrm{Fe} / \mathrm{FeSO}_{4}} \underset{\mathrm{EtOH}}{\longrightarrow} \\
& \mathrm{H}_{2} \mathrm{O} \mathrm{O}^{\mathrm{NH}_{2}}
\end{aligned}
$$

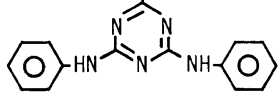

$$
\begin{aligned}
& \underline{D A} \\
& \stackrel{\text { DA }}{\stackrel{\text { 1) } \mathrm{NaH} / \mathrm{DMSO}}{\longrightarrow}} \underset{\text { 2) } \mathrm{n}-\mathrm{C}_{18} \mathrm{H}_{37} \mathrm{Br}}{\longrightarrow} \\
& \text { DA18 }
\end{aligned}
$$

Scheme 1.

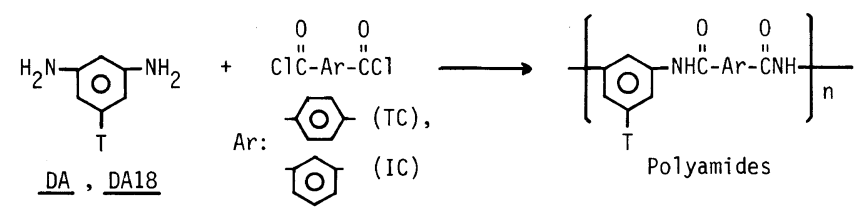

DA, DA18 +


Polyimides (PI)
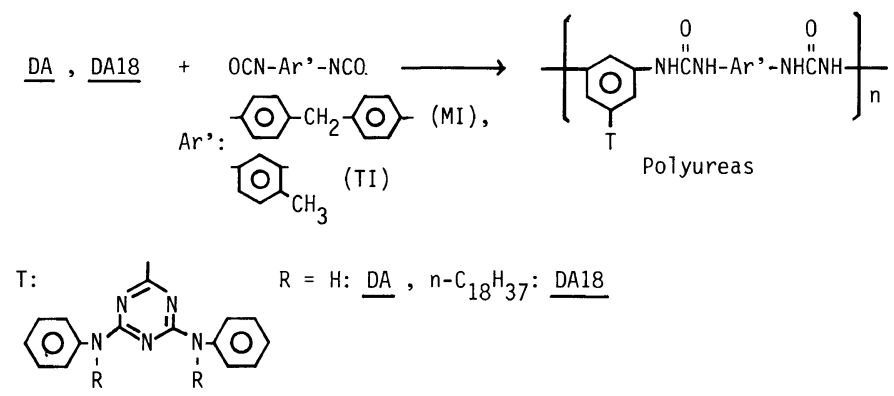

Scheme 2. 
polymerization method. Polyamides were prepared by the polycondensation of diamines DA and DA18 with diacid chlorides TC and IC. Polyimides were prepared by a two-step procedure. In the first step, the polyamic acids
(DA-PA and DA18-PA) were synthesized by the ring-opening polyaddition of DA and DA18 with pyromellitic dianhydride. In the second step, the polyimides were prepared by the thermal cyclodehydration of the corre-

Table I. Preparation of polyamides, polyimide, and polyureas from DA

\begin{tabular}{|c|c|c|c|c|c|c|}
\hline \multirow{2}{*}{ Polymer } & \multirow{2}{*}{$\frac{\text { Yield }^{\mathrm{a}}}{\%}$} & \multirow{2}{*}{$\frac{\eta_{\mathrm{sp}} / c^{\mathrm{b}}}{\mathrm{dl} \mathrm{g^{-1 }}}$} & \multicolumn{3}{|c|}{ Elemental analysis } & \\
\hline & & & $\mathrm{C} \%$ & $\mathrm{H}_{\%} \%$ & $\mathrm{~N} \%$ & \\
\hline $\mathrm{DA}-\mathrm{TC}$ & 93 & 0.20 & 67.99 & 4.41 & 18.66 & \\
\hline \multirow[t]{2}{*}{$\mathrm{DA}-\mathrm{IC}$} & 99 & 0.31 & 67.39 & 4.29 & 18.57 & \\
\hline & & & $(67.30$ & 4.47 & 18.94 & $\left.\mathrm{C}_{29} \mathrm{H}_{21} \mathrm{~N}_{7} \mathrm{O}_{2} \cdot \mathrm{H}_{2} \mathrm{O}\right)$ \\
\hline \multirow[t]{2}{*}{ DA-PA } & 86 & 0.25 & 60.97 & 4.51 & 15.97 & \\
\hline & & & $(61.48$ & 3.82 & 16.19 & $\left.\mathrm{C}_{31} \mathrm{H}_{21} \mathrm{~N}_{7} \mathrm{O}_{6} \cdot \mathrm{H}_{2} \mathrm{O}\right)$ \\
\hline \multirow[t]{2}{*}{ DA-PI } & 90 & 0.31 & 66.75 & 3.47 & 17.60 & \\
\hline & & & $(67.51$ & 3.11 & 17.78 & $\left.\mathrm{C}_{31} \mathrm{H}_{17} \mathrm{~N}_{7} \mathrm{O}_{4}\right)$ \\
\hline \multirow[t]{2}{*}{ DA-MI } & 99 & 0.32 & 69.08 & 4.87 & 19.97 & \\
\hline & & & $(69.78$ & 4.72 & 20.34 & $\mathrm{C}_{36} \mathrm{H}_{29} \mathrm{~N}_{9} \mathrm{O}_{2}$ ) \\
\hline \multirow{2}{*}{ DA-TI } & 98 & 0.28 & 65.73 & 4.76 & 23.05 & \\
\hline & & & $(66.29$ & 4.64 & 23.19 & $\mathrm{C}_{30} \mathrm{H}_{25} \mathrm{~N}_{9} \mathrm{O}_{2}$ ) \\
\hline
\end{tabular}

a Polymerization was carried out with $1.35 \mathrm{mmol}$ of DA and $1.35 \mathrm{mmol}$ of comonomers in $10 \mathrm{ml}$ of DMAc at room temperature for $24 \mathrm{~h}$.

b Measured at a concentration of $0.2 \mathrm{~g} \mathrm{dl}^{-1}$ in DMAc at $30^{\circ} \mathrm{C}$.

Table II. Preparation of polyamides, polyimide, and polyureas from DA18

\begin{tabular}{|c|c|c|c|c|c|c|c|}
\hline \multirow{2}{*}{ Polymer } & \multirow{2}{*}{ Solvent } & \multirow{2}{*}{$\frac{\text { Yield }^{\mathrm{a}}}{\%}$} & \multirow{2}{*}{$\frac{\eta_{\mathrm{sp}} / c^{\mathrm{b}}}{\mathrm{dl} \mathrm{g}^{-1}}$} & \multicolumn{3}{|c|}{ Elemental analysis } & \\
\hline & & & & $\mathrm{C} \%$ & $\mathrm{H}^{\circ} \%$ & $\mathrm{~N} \%$ & \\
\hline DA18-TC & $\mathrm{THF}^{\mathrm{c}}$ & 98 & 0.20 & 76.26 & 9.58 & 9.77 & \\
\hline DA18-TC & NMP & 98 & 0.34 & 76.69 & 9.33 & 9.86 & \\
\hline DA $18-T C$ & $\mathrm{NMP}^{\mathrm{c}}$ & 99 & 0.35 & 76.17 & 9.30 & 9.63 & \\
\hline DA18-TC & THF-NMP $(1: 1)$ & 99 & 0.47 & 77.17 & 9.26 & 9.86 & \\
\hline DA 18-TC & THF-NMP $(1: 1)^{\mathfrak{c}}$ & 99 & 0.50 & 76.76 & 9.56 & 9.68 & \\
\hline DA18-IC & THF-NMP $(1: 1)$ & 97 & 0.22 & 76.65 & 9.46 & 9.42 & \\
\hline \multirow[t]{2}{*}{ DA18-IC } & THF-NMP $(1: 1)^{\mathfrak{c}}$ & 99 & 0.23 & 76.97 & 9.59 & 9.76 & \\
\hline & & & & $(77.72$ & 9.33 & 9.76 & $\left.\mathrm{C}_{65} \mathrm{H}_{93} \mathrm{~N}_{7} \mathrm{O}_{2}\right)$ \\
\hline \multirow[t]{2}{*}{ DA18-PA } & THF-NMP $(1: 1)$ & 98 & 0.17 & 72.54 & 9.02 & 9.72 & \\
\hline & & & & $(73.66$ & 8.58 & 8.97 & $\left.\mathrm{C}_{67} \mathrm{H}_{93} \mathrm{~N}_{7} \mathrm{O}_{6}\right)$ \\
\hline \multirow[t]{2}{*}{ DA18-PI } & & 99 & 0.18 & 76.33 & 8.79 & 9.46 & \\
\hline & & & & $(76.17$ & 8.49 & 9.28 & $\left.\mathrm{C}_{67} \mathrm{H}_{89} \mathrm{~N}_{7} \mathrm{O}_{4}\right)$ \\
\hline \multirow[t]{2}{*}{ DA18-MI } & THF-NMP $(1: 1)$ & 98 & 0.23 & 76.35 & 9.11 & 10.83 & \\
\hline & & & & $(76.89$ & 9.05 & 11.21 & $\left.\mathrm{C}_{72} \mathrm{H}_{101} \mathrm{~N}_{9} \mathrm{O}_{2}\right)$ \\
\hline \multirow[t]{2}{*}{ DA18-TI } & THF-NMP $(1: 1)$ & 99 & 0.22 & 75.32 & 9.40 & 11.94 & \\
\hline & & & & $(75.60$ & 9.32 & 12.02 & $\left.\mathrm{C}_{66} \mathrm{H}_{97} \mathrm{~N}_{9} \mathrm{O}_{2}\right)$ \\
\hline
\end{tabular}

${ }^{a}$ Polymerization was carried out with $1.20 \mathrm{mmol}$ of DA18 and $1.20 \mathrm{mmol}$ of comonomers in $10 \mathrm{ml}$ of the solvent at room temperature for $24 \mathrm{~h}$.

b Measured at a concentration of $0.2 \mathrm{~g} \mathrm{dl}^{-1}$ in THF-NMP $(1: 1)$ at $30^{\circ} \mathrm{C}$.

c $2.50 \mathrm{mmol}$ of triethylamine was added as an acid acceptor. 
sponding polyamic acids at $200^{\circ} \mathrm{C}$ for $6 \mathrm{~h}$ in vacuo. Polyureas were obtained by the polyaddition of DA and DA18 with diisocyanates (MI and TI). The results of DA-polymers and DA18-polymers are listed in Tables I and II, respectively. The mixed solvent of THF-NMP ( $1: 1)$ was found suitable for preparation of the DA18-polymers.

The structures of these polymers were identified by elemental analysis and IR spectra. The results of the analyses agreed with the calculated values. The IR spectra of the polyamides showed typical absorptions of amides at $3450-3200,1660$, and $1320 \mathrm{~cm}^{-1}$. Polyamic acids exhibited absorption bands around $3650-3050,1720$, and $1660 \mathrm{~cm}^{-1}$. These bands disappeared after cyclodehydration and new absorptions were observed at $3450-3250$, 1780,1730 , and $1330 \mathrm{~cm}^{-1}$ associated with the imide structure. Polyureas showed spectrum regions similar to those of polyamides due to ureylene groups. All polymers showed absorption bands of triazine rings at 1410 and $820 \mathrm{~cm}^{-1}$. In addition, DA18-polymers indicated a sharp absorption characterizing the octadecyl groups in the side chain at 2860 $2920 \mathrm{~cm}^{-1}$. The spectral data of all the polymers were consistent with the proposed structures.

\section{Characterization of Polymers}

Solubilities of the polymers were investigated and the results are listed in Table III. All the DA-polymers including polyimide were soluble in polar aprotic solvents such as DMSO, DMAc, $N, N^{\prime}$-dimethylformamide (DMF), and NMP, and concentrated sulfuric acid. The reason for this may be that the presence of the side bulky groups brings about an increase in solubility, ${ }^{10,11}$ compared with those of analogous unsubstituted wholly aromatic polymers. On the other hand, DA 18-polymers having long alkyl side chains exhibited good solubilities in THF, toluene, chloroform, and benzene, but were insoluble in polar aprotic solvents and concentrated sulfuric acid. In addition, all DA18-polymers were easily soluble in mixed solvents of THF-NMP, THF-DMF, and THF-DMAc. The solubilities of DA18-polymers showed obvious change due to the introduction of long alkyl side chains.

The thermal stability of the polymers in air was evaluated by TG and DTA. Typical TG-DTA curves for each of three types of DA-polymers and DA18-polymers are shown in Figures 1 and 2, respectively. The decomposition temperature was determined by a TG curve at a temperature of $5 \%$ weight loss, and

Table III. Solubility of DA-polymers and DA18-polymers ${ }^{\mathrm{a}}$

\begin{tabular}{|c|c|c|c|c|c|c|c|c|c|c|c|c|}
\hline \multirow{2}{*}{ Solvent $t^{b}$} & \multicolumn{6}{|c|}{ DA-Polymers } & \multicolumn{6}{|c|}{ DA18-Polymers } \\
\hline & $-\mathrm{TC}$ & $-I C$ & $-\mathbf{P A}$ & $-\mathrm{PI}$ & $-\mathrm{MI}$ & $-\mathrm{TI}$ & $-\mathrm{TC}$ & $-\mathrm{IC}$ & $-\mathrm{PA}$ & $-\mathrm{PI}$ & $-\mathrm{MI}$ & $-\mathrm{TI}$ \\
\hline DMF & $+t$ & ++ & ++ & ++ & ++ & ++ & - & - & + & - & - & - \\
\hline DMAc & ++ & ++ & ++ & ++ & ++ & ++ & - & - & + & - & - & - \\
\hline DMSO & ++ & ++ & ++ & ++ & ++ & ++ & - & - & \pm & - & - & - \\
\hline NMP & ++ & ++ & ++ & ++ & ++ & ++ & - & \pm & $\overline{+}$ & - & - & - \\
\hline THF & - & - & \pm & - & - & - & \pm & $\bar{t}$ & ++ & ++ & \pm & + \\
\hline Chloroform & - & - & - & - & - & - & \pm & ++ & ++ & ++ & \pm & + \\
\hline Toluene & - & - & - & - & - & - & \pm & ++ & ++ & ++ & \pm & + \\
\hline Benzene & - & - & - & - & - & - & \pm & ++ & ++ & ++ & \pm & + \\
\hline Formic acid & ++ & ++ & ++ & ++ & ++ & ++ & $\overline{-}$ & - & - & - & $\overline{-}$ & - \\
\hline Concn $\mathrm{H}_{2} \mathrm{SO}_{4}$ & ++ & ++ & ++ & ++ & ++ & ++ & - & - & \pm & - & - & - \\
\hline
\end{tabular}

a Solubility: $(++)$ freely soluble; $(+)$ soluble at $60^{\circ} \mathrm{C} ;( \pm)$ partly soluble or swelling; $(-)$ insoluble.

b DMF, dimethylformamide; DMAc, dimethylacetamide; DMSO, dimethyl sulfoxide; NMP, $N$-methyl-2pyrrolidone; THF, tetrahydrofuran. 


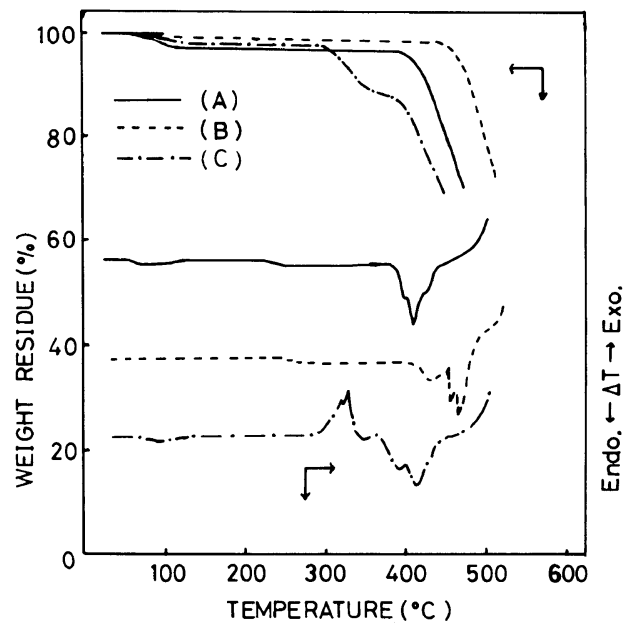

Figure 1. TG and DTA curves of DA-polymers at a heating rate of $10^{\circ} \mathrm{Cmin}^{-1}$ : (A) polyamide DA-TC; (B) polyimide DA-PI; (C) polyurea DA-MI.



Figure 2. TG and DTA curves of DA18-polymers at a heating rate of $10^{\circ} \mathrm{Cmin}^{-1}$ : (A) polyamide DA18-TC; (B) polyimide DA18-PI; (C) polyurea DA18-MI.

the data are listed in Table IV. DA-Polymers were stable up to $430^{\circ} \mathrm{C}$ for polyamides, $480^{\circ} \mathrm{C}$ for polyimide, and $300^{\circ} \mathrm{C}$ for polyureas. The results of thermal stability are very similar to those of previous polymers which contained $1,3,5$-triazine rings in the main chain. ${ }^{12-14}$ DA18-polymers showed lower decomposition temperatures than those of DA-polymers. In a series of polymers, the degree of decrease in
Table IV. Thermal stability of polyamides, polyimide, and polyureas ${ }^{\mathbf{a}}$

\begin{tabular}{lclc}
\hline & $5 \%$ Weight loss & & DA18- \\
DA- & $5 \%$ Weight loss \\
Polymers & ${ }^{\circ} \mathrm{C}$ & Polymers & ${ }^{\circ} \mathrm{C}$ \\
\hline DA-TC & 435 & DA18-TC & 355 \\
DA-IC & 430 & DA18-IC & 335 \\
DA-PI & 485 & DA18-PI & 452 \\
DA-MI & 320 & DA18-MI & 320 \\
DA-TI & 300 & DA18-TI & 305
\end{tabular}

a Recorded by TG in air at a heating rate of $10^{\circ} \mathrm{C} \mathrm{min}^{-1}$.

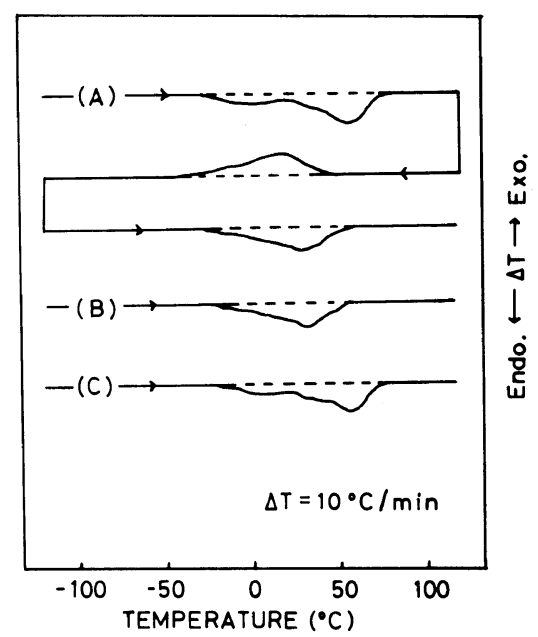

Figure 3. DSC curves of DA 18-MI: (A) repeated from $-120^{\circ} \mathrm{C}$ to $120^{\circ} \mathrm{C}$; (B) standing for $6 \mathrm{~h}$ at room temperature after (A); (C) standing for two weeks at room temperature after (B).

thermal stability due to the introduction of long alkyl side chains is of the following order: polyamide $>$ polyimide $>$ polyurea. On the other hand, the DTA curves of DA18polymers showed small endothermic peaks near $60^{\circ} \mathrm{C}$. These peaks are thought to be the melting of crystals formed by long alkyl groups in the side chains. Therefore, the sidechain crystallization of DA18-polymers was further examined by DSC in the lower temperature region.

Figure 3 shows the DSC curves of polyurea DA18-MI. The polymer sample was precooled at $-120^{\circ} \mathrm{C}$, and heating and cooling experi- 
Table V. Side-chain crystallinity properties of DA18-polymers ${ }^{\mathbf{a}}$

\begin{tabular}{|c|c|c|c|c|c|c|c|c|c|}
\hline \multirow{2}{*}{ Polymer } & \multirow[t]{2}{*}{$T_{\mathrm{m}_{1}}$} & \multirow{2}{*}{$\frac{T_{\mathrm{cr}}}{{ }^{\circ} \mathrm{C}}$} & \multirow[t]{2}{*}{$T_{\mathrm{m}_{2}}$} & \multicolumn{3}{|c|}{$\Delta H^{\mathrm{b}}\left(\mathrm{kcal} \mathrm{mol}^{-1}\right)$} & \multicolumn{3}{|c|}{$n_{\text {cryst }}{ }^{\mathrm{c}}$} \\
\hline & & & & $\Delta H_{1}$ & $-\Delta H_{\mathrm{cr}}$ & $\Delta H_{2}$ & $n_{1}$ & $n_{\mathrm{cr}}$ & $n_{2}$ \\
\hline DA18-TC & 71 & -21 & 4 & 1.18 & 1.47 & 1.80 & 0.80 & 1.00 & 1.22 \\
\hline DA18-IC & 4 & -11 & 2 & 1.81 & 1.97 & 2.06 & 1.23 & 1.34 & 1.40 \\
\hline DA18-PA & 60 & 2 & 5 & 3.54 & 3.15 & 3.48 & 2.41 & 2.14 & 2.37 \\
\hline DA18-PI & 15 & -22 & -8 & 4.16 & 1.79 & 1.44 & 2.83 & 1.22 & 0.98 \\
\hline DA18-MI & 62 & 15 & 27 & 2.57 & 2.31 & 2.28 & 1.75 & 1.57 & 1.55 \\
\hline DA18-TI & 63 & 15 & 28 & 2.91 & 2.11 & 2.23 & 1.98 & 1.43 & 1.52 \\
\hline
\end{tabular}

a Measured by DSC from -120 to $120^{\circ} \mathrm{C}$ at a rate of $10^{\circ} \mathrm{Cmin}^{-1}$.

b Enthalpies of fusion and crystallization of side chains.

c Numbers of crystallized methylene groups.

ments were then repeated at a rate of $10^{\circ} \mathrm{Cmin}^{-1}$. All DA18-polymers showed endothermic and exothermic peaks during heating and cooling, respectively, indicating the melting and crystallization of the alkyl side chains. For the endothermic peak near $60^{\circ} \mathrm{C}$ in the first run, it is assumed that the crystalline structure formed at room temperature on standing after polymerization, because this endothermic peak reappeared after measurement of DSC and stood at room temperature for two weeks (Figure 3).

The melting and crystallization temperatures of long alkyl side chains $\left(T_{\mathrm{m}_{1}}, T_{\mathrm{cr}}\right.$, and $T_{\mathrm{m}_{2}}$ ) were determined by the tops of the peaks of DSC curves. The results of DSC measurements are summarized in Table V. It has been reported that the alkyl side chains of comb-like polymers crystallize in hexagonal form. ${ }^{1-5}$ In order to estimate the numbers of crystallized methylene groups $\left(n_{\text {cryst }}\right)$ in the side chains of these polymers, we assumed that the long alkyl side chains crystallize in hexagonal form in this work. The $n_{\text {cryst }}\left(n_{1}, n_{\text {cr }}\right.$, and $\left.n_{2}\right)$ was evaluated from the enthalpies of fusion and crystallization $\left(\Delta H_{1}, \Delta H_{\mathrm{cr}}\right.$, and $\left.\Delta H_{2}\right)$ using the value $\left(735 \mathrm{cal} \mathrm{mol}^{-1}-\mathrm{CH}_{2}\right.$ ) reported for the transition enthalpy of $n$-alkane from hexagonal packing to a liquid. ${ }^{15}$ The degree of crystallinity calculated from the values of $n_{2}$, which have the same thermal histories, was $5-13 \%$ on the basis of the alkyl side chains in these polymers.
The value of $n_{2}$ for DA18-TC was noted to be lower than the DA18-IC, DA18-PI lowder than DA18-PA. In addition, the polyureas showed higher $n_{2}$ values than those of polyamides and polyimide. As an extreme example, for comb-like vinyl polymers, the degree of side-chain crystallinity has been shown to be $41 \%$ for poly(octadecyl acrylate) ${ }^{5}$ and $25 \%$ for poly $\left(N\right.$-octadecylacrylamide) ${ }^{5}$ On the other hand, this value was only $9 \%$ for $N$ octadecylated poly( $p$-phenylene terephthalamide $)^{7}$ which contains typical rigid backbone. This might be because the rigid structure in the main chain depresses side-chain crystallization, resulting in a low degree of crystallinity. Therefore, the findings that the $n_{2}$ values of polyamides and polyimides are lower than those of polyureas would be explained by their relatively rigid backbone structures.

\section{REFERENCES}

1. C. G. Overberger, L. H. Arond, R. H. Wiley, and R. R. Garrett, J. Polym. Sci., 7, 431 (1951).

2. S. A. Greenberg and T. Alfrey, J. Am. Chem. Soc., 76, 6280 (1954).

3. E. F. Jordan, Jr., D. W. Feldeison, and A. N. Wrigley, J. Polym. Sci., A-1, 9, 1835 (1971).

4. E. F. Jordan, Jr., D. W. Feldeison, and A. N. Wrigley, J. Polym. Sci., A-1, 9, 3349 (1971).

5. N. A. Platé and V. P. Shibaev, J. Polym. Sci., Macromol. Rev., 8, 117 (1974).

6. M. Takayanagi and T. Katayose, J. Polym. Sci., Polym. Chem. Ed., 19, 1133 (1981). 
7. M. Takayanagi and T. Katayose, J. Appl. Polym. Sci., 29, 141 (1984).

8. J-K. Lin, H. Kunisada, S. Kondo, and Y. Yuki, Kobunshi Ronbunshu, 45, 831 (1988).

9. F. H. S. Curd and F. L. Rose, J. Chem. Soc., 729 (1946).

10. P. M. Herbenrother, Macromolecules, 7, 575 (1974).

11. Y. Oishi, M. Kakimoto, and Y. Imai, J. Polym. Sci., $A, 25,2493$ (1987).
12. Y. Yuki, S. Sakuri, T. Kakurai, and T. Noguchi, Bull. Chem. Soc. Jpn., 43, 2130 (1970).

13. Y. Yuki and S. Mouri, Nippon Kagaku Kaishi, 2181 (1974).

14. Y. Yuki and M. Kinoshita, Nippon Kagaku Kaishi, 549 (1977).

15. M. G. Broadhurst, J. Res. Nat. Bur. Stand., 66A, 241 (1962). 